\title{
A HISTORIA DA EDUCACIÓN EN GALICIA. NOTAS PARA UNHA REVISIÓN HISTORIOGRÁFICA
}

\author{
por \\ ANTÓN COSTA RICO
}

\section{A CONVENIENCIA DA REVISIÓN*}

Hai só dez anos non habería apenas lugar a se deter sobre a conveniencia de realizar unha revisión da historiografía educativa de Galicia.

Daquela, a catalogación dos traballos e aportacións para unha historia da educación en Galicia resumíase nun pequeno molliño de fichas documentais, tanto pola encaseza de aportacións como pola dificultade de coñecer o seu soporte editorial, en todo caso excesivamente viradas para a erudición local positivista.

Destora, mudou aquel panorama case radicalmente, por mais que se esteña aínda distante do meridiano previsible dos inquéritos considerados importantes e aínda a facer, para eliminar as lagoas de coñecemento de maior calado neste eido do pasado educativo e pedagóxico de Galicia.

E por iso que, á vista das mais de duascentas aportacións de investigación, sexa conveniente facer unha reflexión e unha revisión sobre o coñecemento acadado e sobre as conclusións da investigación, a fin, en primeiro termo, de facer reconto cun criterio informativo, pois que esta información non se acha actualmente a disposición normal dos estudosos

* Debo agradecer as consideracións ó primeiro borrador por parte dos colegas e amigos Drs. Narciso de Gabriel e Vicente Peña, porque contribuiron a enriquece-lo presente texto. As "notas" acadan ata á fin de 1991. A elaboración definitiva fíxose en 1992.

"CUADERNOS DE ESTUDIOS GALLEGOS", Tomo XLI, Fascículo 106, Santiago 1993-94. 
e dos estudantes de historia da educación. Parece tamén oportuno poder valorar a calidade, o interese e a productividade das investigacións e dos achegamentos realizados e do coñecemento elaborado, de tal modo que operando como diagnóstico deste sector de investigación histórica -para mellor comprender o presente educativo de Galicia-, se poidan tracexar liñas significativas e productivas para o desenvolvemento da investigación histórica educativa de Galicia. Con esto, permitiráselle tamén á comunidade científica ter unha visión e unha comprensión máis obxectiva sobre o acontecer educativo, ó que están a contribuir os actuais estudos galegos de "historia local e social" da educación, como academicamente se recoñece.

\section{A PRODUCCIÓN BIBLIOGRÁFICA}

Na actualidade a producción bibliográfica relativa á historia Contemporánea da educación en Galicia acada un total de 145 referencias, nas que podemos distinguir 26 libros, 20 contribucións en libros de diversa temática —case sempre de caracter histórico-, 70 contribucións publicadas en revistas, e 29 contribucións editadas en libros de Actas de Congresos e Xornadas de caracter histórico, amáis de catro folletos.

Compre salientar que este total de 145 referencias foi elaborado por un total de 57 autores, anque somentes once deles veñen adicando unha atención continuada á investigación e ó tratamento de diversos aspectos da historia da educación en Galicia, cun total de 97 referencias (o 68\% do total delas) ${ }^{1}$. Aínda dentro dos anteriores é mester salientar que cinco autores realizaron 69 contribucións; é dicir un $9 \%$ do total dos autores elaboraron case a medade de toda a producción histórica que analizamos ${ }^{2}$.

A este tratamento bibliográfico poderiamos sumar a existencia de 23 tesinas de licenciatura presentadas desde os anos sesenta nas Universidades de Madrid, Barcelona, Salamanca e Santiago, con temática educativa galega ou de estudo de autores galegos (Feijoo, Sarmiento, Concepción

\footnotetext{
${ }^{1}$ Son eles: X.R. Barreiro Fernández, C. Benso Calvo, X.M. Cid Fernández, A. Costa Rico, N. de Gabriel, Meijide Pardo, V. Peña Saavedra, M.C. Pereira Domínguez, A.S. Porto Ucha, M. Suárez Pazos e Isaura Varela.

${ }^{2}$ Os 5 autores cunha producción de 10 ou máis contribucións son: X.M. Cid Fernández, A. Costa Rico, De Gabriel, V. Peña Saavedra e A.S. Porto Ucha.
} 
Arenal...) $)^{3}$, cinco teses de Doutoramento sen publicar como tales ${ }^{4}$, cinco artigos, que son a transcrición de textos históricos relativos a aspectos diversos da educación en Galicia ${ }^{5}$ e algúns artigos de prensa ${ }^{6}$, o que elevaría a cifra de referencias a algo máis de 180 .

Anque aquí non consideramos os estudos e aportacións referidas á momentos anteriores á Ilustración, non está sobrado poñer de manifesto a existencia de 50 aportacións tamén diversas ${ }^{7}$, das que 22 se centran no

${ }^{3}$ As tesiñas realizadas refírense en varios momentos ás obras de Sarmiento, Feijoo, Emilia Pardo Bazán; noutros casos e por unha soa vez son $\mathrm{M}^{\mathrm{a}}$ Barbeito, Concepción Arenal, Joaquín Avendaño, Vicenti e a Xeneración Nos ás persoaxes ou colectivos analizados. Outras temáticas aluden á Ilustración na Universidade de Santiago, ó ensino primario en Santiago no século XIX, á dotación de medios didácticos e de material nas escolas de Santiago na Alta Restauración, á evolución dos estudios eclesiásticos na Arquidiócese de Santiago, ó nacemento do Instituto de Santiago, ó ensino medio en Lugo a mediados do século XIX, á laboura educativa dos emigrantes na provincia de Lugo, á Universidade durante o Sexenio Revolucionario, ó Seminario de Santiago no período 1829-1868, á prensa educativa en Vigo entre 1927 e 1936, á Universidade durante o periodo Isabelino, ó ensino primario na cidade da Coruña no mesmo período.

${ }^{4}$ As teses, son as dos profesores X.M. Cid (1987), Sánchez Rodríguez de Castro (1990), M. Suárez Pazos (1982), X. Torres Santomé (1979) e Antón Costa (1982), arredor das temáticas: a educación en Ourense durante a II ${ }^{\mathrm{a}}$ República, a obra educativa do Consulado do Mar da Coruña (1785-1815), a educación en Galicia no Sexenio Revolucionario, a educación e a Sociedade Económica de Amigos do País de Santiago e a educación primaria no primeiro tercio do século XX, respectivamente.

${ }^{5}$ No relativo á publicación de fontes e textos de época debemos aludir á obra Política y Pedagogía de Fernández Mazas (Ourense, 1990), Viaje por las escuelas de Galicia con textos de Luis Bello de 1929, Historia viva do Instituto de Lugo de Fernández Pinedo, Abajo las Dictaduras da mestra republicana García Segrel e o texto da oposición de Cátedra do médico José Varela de Montes.

${ }^{6}$ Entre os artigos de prensa poderiamos citar referencias ó Congreso Pedagóxico de Pontevedra de 1887, ós vincallos galegos de X.M. Cossío, á pedagoxía dos xesuitas en Camposancos e a memoria dos mestres mortos e separados do ensino en 1936, da autoría de Porto Ucha, José A. Durán e Antón Costa.

${ }^{7}$ Hai tres traballos que se achegan ás escolas catedralicias, un ós seminarios de Galicia (o seu nacemento), un ós estudios dos dominicos, un ós dos mercedarios, un á educación dos expositos, un á educación primaria en Santiago nos séculos XVI-XVIII e outro a mesma educación en Ourense; dous á cultura en Galicia no século XVI, un ás Escolas do Mosteiro de Oseira, oito ás cátedras de gramática e outras nas vilas de Viveiro, Betanzos, Quiroga, Pontevedra, Vilagarcía e Noia e finalmente, xunto as referencias ó estudio da Universidade de Santiago, hai 7 traballos que se refiren á formación e escolas dos xesuitas, incluíndo un groso e ben documentado libro da autoría de Rivera Vázquez sobre os colexios dos xesuitas en Galicia entre os séculos XVI-XVIII.

"CUADERNOS DE ESTUDIOS GALLEGOS", Tomo XLI, Fascículo 106, Santiago 1993-94. 
estudo de diversos aspectos da Universidade de Santiago ${ }^{8}$.

Se descontamos os libros, saídos do prelo no marco das máis destacadas coleccións editoriais na actualidade existentes en Galicia, compre anotar a ampla diversidade de lugares de edición e de soporte editorial para as referencias da historia educativa ás que aludimos, se ben ocupan particular relevancia as revistas das institucións museísticas case sempre provinciais de Galicia, da Real Academia Galega, do Instituto de Estudos Galegos Pai Sarmiento, a revista da Sociedade Española de Pedagoxía Bordón que prestou algunha atención ós estudos de historia da educación en Galicia ( ${ }^{\circ} 253$ de 1984), así como o anuario Historia de la Educación e os libros de Actas (seis polo momento) dos "Coloquios de Historia de la Educación" organizados pola "Sociedad Española" respectiva, como foi o caso do último: Mujer y Educación en España, 1868-1975 (Santiago de Compostela, 1991).

No seu conxunto trátase dun producto editorial moi desigual tanto polo seu tamaño como polo valor científico.

\section{A TEMÁTICA HISTÓRICO-EDUCATIVA}

Compre poñer de manifesto a variedade temática analizada como tamén a diversidade do seu tratamento.

En todo caso, podemos sinalar a atención preferente concedida ós seguintes tópicos: o ensino primario e a escolarización no tempo da Alta e Baixa Restauración e durante a II ${ }^{\mathrm{a}}$ República Española, o ensino universitario desde as reformas ilustradas ata a fin da II ${ }^{\mathrm{a}}$ República, a galeguización lingüística e curricular do sistema educativo con dous polos de atención, un relativo á figura e escritos do Pai Sarmiento e, outro, sobre a dinámica de paulatina galeguización desde o nacemento das "Irmandades da Fala" (1916) ata a fin da II República, os debates ideolóxico e científico e a incorporación das ciencias físico-naturais no marco da Universidade de

\footnotetext{
${ }^{8}$ Das 22 referencias de estudo universitario, entre as que se contan 5 libros, hai que salientar a boa presencia de arquiveiros e historiadores universitarios, como tamén de frades profesores, empregando arreo unhas boas dotes de erudición para con criterios positivistas analizar aspectos relativos á poboación universitaria, Constitucións, Cátedras, Colexios e colexiais, a Biblioteca, os Arzobispos, a Igrexa e a Universidade, o consumo alimenticio, á presencia das ordes relixiosas na Universidade, e outros aspectos de interese.
} 
Santiago, o desenvolvemento do ensino relixioso a través dos seminarios, os discursos e as prácticas de educación femenina e os procesos da incorporación da muller no sistema educativo, a impronta educativa dos emigrantes galegos en América e a súa acción, e tamén, o ensino técnico e profesional en distintos momentos do século XIX.

Máis descritivamente, anotamos que das 145 referencias de investigación sinaladas, 16 adicanse a diversas aportacións relativas ó desenvolvemento da Universidade de Santiago ${ }^{9}$. Referencias que poden ampliarse en sete máis referidas ós debates ideolóxicos, á incorporación dos métodos científicos experimentais na Universidade, asi como tamén á producción científica universitaria ${ }^{10}$.

A análise do desenvolvemento do ensino primario e da súa problemática e incidencias é hoxe medianamente extensa, amáis de estar seriamente construída; entre os investigadores anotamos os nomes de Mercedes Suárez Pazos, Narciso de Gabriel, Antón Costa e Xosé Manuel Cid. Respectivamente atenderon á problemática e desenrolo da escolarización durante o Sexenio, á Alta Restauración, ó primeiro tercio de século XX e a II $^{\text {a }}$ República ${ }^{11}$.

\footnotetext{
${ }^{9}$ Son de destacar aquí o estudo institucional sistemático, erudito e de recollida documental de Cabeza de Leon e Fernández Villamil, estudio xa clásico para o coñecemento da Universidade de Santiago, ben que a obra poida ser revisada en base ós criterios metodolóxicos da historia social. De forma similar hai que destacar a obra dirixida polo profesor Manuel Díaz y Díaz con aportacións que tratan de amosar o desenvolvemento da Universidade de Santiago, entre as que destacariamos as de Barreiro Fernández —o mellor coñecedor das reformas ilustradas en Santiago- as de Martínez Rodríguez e as de Ofelia Rey Castelao. A obra editada ten unha moi boa calidade gráfica e documental, sendo de referencia obrigada tamén debido ao seu apartado de fontes e bibliografía. Polo seu animo de sistematización e de recuperación documental a respeito do devir da Universidade hai que citar entre outros os traballos dos profesores universitarios Viñas e Bustamante. Isaura Varela ven destacándose como analista da dinámica universitaria compostelana ó longo do primeiro tercio do século cun tratamento desde as perspectivas metodolóxicas fructíferas da historia social.

${ }^{10}$ Ó respeito, pioneras e valiosas son as aportacións dos profesores universitarios Díaz Fierros e Barreiro Fernández. Diversos aspectos son analizados por Purificación Mayobre e Xosé A. Fraga. Unha pequena monografía de síntese foi construída por Costa Rico.

"Como temas abordados con particular atención podense anotar por parte de Mercedes Suárez o estudo de incorporación da muller ó sistema escolar, o campesiñado ante a escola e os aspectos político-lexislativos da educación no Sexenio (1868-1874). Por parte de Narciso de Gabriel suliñamos o estudo das escolas de ferrado, a cuestión metodolóxica escolar, a problemática da escolarización e do profesorado na escola rural, as estadísticas, a calidade escolar e os resultados educativos e o papel da muller, todo iso no marco da
} 
Arredor da galeguización podemos anotar unha ducia de referencias: o tratamiento das figuras e obras de Sarmiento e de Viqueira, as prácticas lingüísticas, a presencia do galego e as posicións do que podemos denominar como "o galeguismo" ante os debates e a política educativa, conforman os tópicos de análise ${ }^{12}$.

Lugar notable na investigación educativa ten o capítulo dos emigrantes, o seu pensamiento educativo e a súa acción escolar en Galicia, cun investigador de relevo, Vicente Peña. Son tamén unha ducia de referencias as que estudan este importantísimo aspecto da evolución educativa contemporáneo de Galicia ${ }^{13}$.

O sistema educativo foise construíndo baixo as orientacións políticoadministrativas emanadas do Goberno Central. De aí, as prácticas dominantes, case sempre deficientemente operativizadas en Galicia. Tamén tal sistema estivo aberto a influencias renovadoras singularmente inspiradas pola Institución Libre de Ensino, e outras correntes como a Ilustración, as orientacións socialistas e anarco-sindicalistas, ou a Escola Nova Europea. Isto mereceu atención sistemática no caso da I.L.E. por parte de Porto Ucha, se ben son varios os investigadores que atenderon a estas cuestións ${ }^{14}$.

escola de finais do século XIX. Antón Costa abordou con perspectiva globalizada o conxunto da dinámica escolar sobre todo no primeiro tercio do século, con apertura por iso á $\mathrm{II}^{\mathrm{a}}$ República; xunto ós aspectos infraestructurais, será o estudo do profesorado como protagonista e a incorporación da renovación pedagóxica, aqulo máis estudado. Pola súa parte Xosé Manuel Cid ten estudado con detemento o proceso de cambios na escola ourensán en particular no período 1915-1936; os cambios materiais, metodolóxicos e os debates entre filosofías educativas contradictorias, comasí entre os protagonistas.

${ }^{12}$ Son destacables as aportacións de Filgueira Valverde, de Filgueira Iglesias, de Sánchez Cantón, da profesora Galino, de Torres Regueiro, de Narciso de Gabriel, de Xosé Manuel Cid e de Antón Costa.

${ }^{13}$ Xunto a Vicente Peña, destaca polo seu estudo institucional de Valle Miñor, M $^{\mathrm{a}}$ Carme Pereira. Outras aportacións son de Liñares e de Porto Ucha. Costa Rico fixo a inicial aportación global e de sistematización para o estudo desta temática...

${ }^{14}$ Xunto ó estudo sistematizador de Porto Ucha, quen presta tamén unha particular atención á formación do profesorado a través das Escolas Normais e dos Congresos Pedagóxicos e á influencia a Escola Nova Europea, podemos citar aportacións de $\mathrm{M}^{\mathrm{a}} \mathrm{Carme}$ Pereira sobre as Colonias Escolares en Galicia, de Uxío Otero Urtaza sobre as Misións Pedagóxicas, de Xosé Manuel Cid sobre pensamento e acción escolar racionalista e socialista en Ourense, de Antón Costa sobre o laicismo escolar e o pensamento socialista e a súa acción escolar en Galicia, atendendo tamén á formación do profesorado, debendo salientar que á análise da Ilustración fora dos estudos universitarios, non se adicaron estudos, agas as varias e non sempre óptimas aportacións sobre a figura do P. Feijoo.

"CUADERNOS DE ESTUDIOS GALLEGOS", Tomo XLI, Fascículo 106, Santiago 1993-94. 
A Igrexa católica foi un axente de primeiro orde canto á educación, cousa que na Galicia contemporánea terá o seu expoñente singularmente destacado nos Seminarios e na educación catequética, máis que na acción dos colexios de ensino relixioso ou no pensamiento educativo ${ }^{15}$.

A incorporación da muller á educación e os modelos de educación feminina mereceron a atención en particular de Mercedes Suárez, de Carme Benso e de Narciso de Gabriel.

O ensino técnico e profesional foi estudado arredor de catro dimensións/ iniciativas: a acción desenvolvida polo Real Consulado do Mar da Coruña, excepcionalmente estudado por Sánchez de Castro, as Escolas Náuticas, coas aportacións documentais sempre rigorosas de Meijide Pardo, o nacemento e primeiros pasos das Escolas de Artes e Oficios e a formación profesional agraria, neste caso da man de Narciso de Gabriel en relación coa escola primaria e de L. Fernández Prieto a respeito da Granxa-Escola de A Coruña ${ }^{16}$.

Outros temas mereceron un tratamiento menor: o desenvolvemento da prensa escolar e pedagóxica ${ }^{17}$, o papel das Deputacións a respeito do desenvolvemento educativo ${ }^{18}$, a educación dos nenos hospiciados en Santiago, a evolución local da educación en vilas como Ortigueira, Cée, Betanzos, Negreira, Ribadeo ou na cidade de Ourense, a difusión da Constitución no período 1820-23, o nacemento e primeiros pasos dos Institutos de ensino secundario en Santiago e na Coruña (destacando as aportacións de Fariña Casaldarnos), a represión franquista sobre o profesorado e a escola franquista $^{19}$, os ecos en Galicia de Revolución Francesa ${ }^{20} \mathrm{e}$ a análise dos niveis de alfabetización en Galicia, como traballo único de González Gelabert

\footnotetext{
${ }^{15}$ Quizais sexan as aportacións de García Cortés sobre o Seminario de Santiago as mellor construídas. Debemos anotar escritos de Couselo Bouzas, de Gonzalo Fraga, de Porto Ucha, e de Barreiro Fernández.

${ }^{16}$ Sobre as Sociedades Económicas e as Escolas de Artes e Oficios hai un estudo inédito de Jurjo Torres con atención á de Santiago e hai aportacións editadas de Fernández Casanova, Porto Ucha e Sousa e Pereira, ésta última se cadra a máis interesante. Sobre a formación agraria fixeron aportacións Narciso de Gabriel, Lourenzo F. Prieto e Antón Costa. Pola súa parte Meijide Pardo atendeu ó desenrolo das Escolas de Debuxo.

${ }^{17}$ Con aportacións de M.C. Pérez Pais, Vicente Peña e Antón Costa.

${ }^{18} \mathrm{O}$ estudo de Prado González sobre o caso da Deputación de Lugo.

${ }^{19}$ Podense anotar aquí os traballos de $\mathrm{M}^{\mathrm{a}}$ Carme Benso e de Costa Rico.

${ }^{20} \mathrm{Ou}$ a lectura de libros prohibidos en Galicia como aportación de Porto Ucha e mesmo a máis recente de Meijide Pardo sobre a emigración do clero francés a Galicia.
}

"CUADERNOS DE ESTUDIOS GALLEGOS", Tomo XLI, Fascículo 106, Santiago 1993-94. 
que, anque centrado na Galicia do Antigo Réxime penetra na etapa contemporánea.

Se doutro modo analisamos a temática, podemos observar neste percorrido a presencia do estudo de diversas institucións educativas en si mesmas, xunto ó estudo das ideas e debates educativos, das prácticas de educación e dos actores da educación, sendo estes os menos estudados e as ideas e os debates o capítulo mais abordado (con cerca de 50 referencias).

\section{¿Qué pode isto querer dicir?}

En positivo, que o tratamiento e o estudo que ata o presente se realizou arredor das institucións, das ideas, dos actores da educación e das prácticas, anque non plenamente equilibrado, é indicio de andar nunha perspectiva correcta do punto de vista da investigación histórica educativa, ó ir máis aló dunha historia meramente institucional, cronolóxica, descritiva e unidimensional, para procurar, polo contrario, o estudo de temas clave e a comprensión das diversas situacións históricas.

Como deficiencias habería que apontar que o predominio do estudo das ideas educativas e pedagóxicas sobre as outras dimensións pode vir motivado polo insuficiente avance da investigación. O menor peso da investigación centrada sobre as prácticas escolares e sobre os actores é posiblemente debido á maior dificultade de localización e de análise das fontes primarias manuscritas, que só unha maior atención á realización de monografías e ensaios de microhistoria pode permitir superar. É dicir, vai sendo o momento de penetrar nos arquivos das institucións escolares, da administración local, das administracións relixiosas e nos arquivos familiares para contrastar mais de preto aquilo que realmente ten sucedido no día a día dos procesos educativos e escolares, interpretándoo contextualmente.

Pódese tamén sinalar a atención concedida por este orde ó ensino universitario, primario, técnico, profesional e relixioso, facéndose notar a escaseza ou carencia de estudos adicados ó ensino medio, á educación especial e á educación preescolar.

Desde o ponto de vista temporal e como xa en certo modo se sinalou, as investigacións sitúanse en particular no período que vai desde o inicio da Restauración (1875) ó remate da Segunda República (1936), estando por estudar practicamente a historia da educación no período que vai desde o reinado de Carlos III ata a aprobación da Lei Moyano (1857), como tamén desde os momentos da Guerra Civil (1936) ata os anos setenta. 
Desde o punto de vista espacial e máis alá das investigacións sobre a Universidade de Santiago e sobre as institucións culturais e educativas xa aludidas, concreta ou xenericamente, abondan as referencias para $o$ conxunto de Galicia, namentras que escasean os estudos con referencia xeográfica urbana, local e comarcal concreta, coas excepcións de rigor ${ }^{21}$.

\section{¿Qué campos e temáticas compriría estudar con máis intensidade?}

Se cadra non as cuestións de política, lexislación e organización escolar nos ensinos primario e universitario, máis si nos outros niveis e modalidades educativas; as cuestións didácticas e metodolóxicas; os aspectos biográficos; a evolución de moitas institucións escolares públicas e particularmente privadas atendendo neste caso, ós promotores, ó seu público, a súa razón de ser e función social, as súas características pedagóxicas. Hai que estudar o ensino secundario, a educación especial e a educación preescolar, e profundizar na educación técnico-profesional, con atención singular ós casos de Ferrol e Vigo. Faltan investigacións sobre os Seminarios de Mondoñedo, de Tui e de Ourense, e sobre outras casas de formación relixiosa. Carecemos dun estudo en torno das Escolas Normais de Galicia, e de monografías sobre os profesores e profesoras (orixe social, edades, pensamento, status social...). A inspección educativa, a educación moral, a educación sanitaria a traverso da escola, a visión do mundo, a educación cívica, o emprego de medios e recursos didácticos, a educación de adultos, ou a educación non formal... son outros tantos tópicos que están agardando a realización das adecuadas monografías.

\section{AS FONTES DE INVESTIGACIÓN HISTÓRICO-EDUCATIVA}

A historia contemporánea da educación en Galicia construída ata o presente é en boa medida debedora das fontes impresas máis que das manuscritas, ben que o conxunto de investigadores teñen empregado tanto unhas como outras.

\footnotetext{
${ }^{21}$ Nas referencias concretas hai que citar a Santiago, a Ourense, a Betanzos, a Ortigueira, a Negreira, ó Val Miñor... máis seguen a faltar monografías sobre A Coruña, Ferrol, Lugo, Vigo, Pontevedra e tantos outros lugares, por máis que aquí e aló existan referencias interesantes. $\mathrm{O}$ aqui e aló apórtano os investigadores que xa temos citado en varias ocasións.
}

"CUADERNOS DE ESTUDIOS GALLEGOS", Tomo XLI, Fascículo 106, Santiago 1993-94. 
Dentro das manuscritas teñen un particular relevo as de caracter administrativo, tanto emanadas dos órganos provinciais da administración do ensino ou os da administración educativa universitaria, como a documentación manuscrita dirixida a estas administracións de por parte dos particulares e centros escolares interesados. Pola contra, e reducida a análise da documentación manuscrita de caracter local-municipal ou propiamente individual, a modo de memorias e outros documentos das singulares institucións educativas; no que fai relación á documentación impresa, e sempre con atención á temática actualmente estudada, abonda o estudo de obras, informes, documentación social estadística, documentación xurídicolegal, e documentación hemerográfica ofrecida polos centos de cabeceiras de prensa periódica e diaria editadas en todo o período da historia contemporánea de Galicia.

De facer unha recomendación, parecería oportuno realizar un aproveitamento máis fino da documentación hemerográfica propiamente escolar e educativa e da de autoría eclesiástica. Do mesmo modo, se cadra é oportuna unha maior atención ás fontes impresas literarias, como oportunamente ten recordado o profesor de historia da educación Herminio Barreiro.

Se facemos mención ós centros documentais utilizados, compre salientar o relevo tanto da Biblioteca Universitaria de Santiago como do Arquivo da mesma Universidade. A eles sumaremos as Bibliotecas da Real Academia Galega, do Instituto de Estudios Galegos Pai Sarmiento, da Fundación Penzol, do Consulado do Mar, do Museo de Pontevedra, asi como a Provincial e o Arquivo Provincial pontevedrés e os Arquivos do Reino de Galicia e Provincial de Ourense. Menor espacio ocupan xa a Biblioteca e o Arquivo Pronvincial de Lugo, asi como os centros situados en Madrid como son a Biblioteca Nacional, a Real Academia da Historia, asi como o Arquivo Histórico Nacional e o Arquivo Central do Ministerio de Educación en Alcalá de Henares, de todos modos, insuficientemente empregados.

Parecía oportuno intensificar o emprego dos recursos documentales existentes nos centros estatais radicados en Madrid, no Arquivo de Tordesillas, nos Arquivos Catedralicios, e sobre todo dos existentes nos arquivos das Dióceses galegas, nos arquivos conventuais mais que nos monásticos, coma os de Santiago, Padrón, Poio, Ribadeo e outros, nos Arquivos da administración local, nos notariais e de rexistro mercantil e os propios de diversas institucións educativas relixiosas. Por suposto están agardando a súa explotación os fondos dos Institutos provinciais de 
Bacharelato e os das Escolas Normais ${ }^{22}$. En canto ás Hemerotecas, se ben o traballo ten sido amplo ${ }^{23}$, parecería bo profundizar a análise hemerográfica de coleccións como La Voz de Galicia e El Correo Gallego ó estar xa analizadas as outras "grandes" cabeceiras de prensa galega. Compre tamén impulsar a búsqueda, consulta e vaciado da prensa local, ante a febleza da súa conservación, como testigo da historia.

\section{UNHA OBSERVACIÓNS SOBRE A METODOLOXÍA DA IN- VESTIGACIÓN E SOBRE OS INVESTIGADORES}

Estamos diante dunha historia da educación metodolóxicamente inspirada na pasada década dos anos oitenta pola corrente afecta á historia social da educación. Hai un afan interpretativo certo e un esforzo por considerar os marcos teóricos historiográficos e contextuais. Rexístrase un afán por construir unha historia-problema dentro dunha visión ampla de nova historia. Con todo, e se ben podemos aludir á ausencia do idealismo, no conxunto de toda a producción anterior e actual pesa máis o historicismo e o positivismo que a construcción de modelos históricos interpretativos, extremo que pode ser explicado tanto pola xuventude deste capítulo de estudo histórico, como polas insuficiencias formativas no terreo da investigación histórica dos que exercen o oficio de investigadores, que son en maior medida e actualmente especialistas das ciencias da educación mais non inicialmente historiadores en canto á súa formación universitaria. Isto podería parcialmente explicar por exemplo o menor emprego de fontes manuscritas ou mesmo o moi escaso alento dos estudos da historia da educación na Galicia da Idade Media ou do Antigo Réxime, para o que serían precisos coñecementos de paleografía e diplomática ou unha mais sólida formación histórica xeral da que conmunmente se carece.

Así podemos resaltar como é nestes casos que son outros os investigores

${ }^{22}$ Ó respeito, un traballo de ordenación documental do Arquivo da Escola de Santiago aínda inacabado, promoveuse polo profesor Antón Costa no ano 1988. Porto Ucha realizou unha similar acción na Escola Normal de Pontevedra.

${ }^{23}$ Quizais os traballos máis intensos de caracter hemerográfico son os desenvolvidos por Narciso de Gabriel, Antón Costa e Vicente Peña Saavedra. Este último dentro das actividades de clase como profesor de Historia da Educación ten promovido un amplo e vigoroso estudo, polo que hoxe existe un grande capital documental desta modalidade na Sección de Pedagoxía da Facultade de Filosofía e Ciencias da Educación.

"CUADERNOS DE ESTUDIOS GALLEGOS", Tomo XLI, Fascículo 106, Santiago 1993-94. 
que teñen realizado algunha aportación. Aportación, neste caso, máis apegada ó historicismo e dominada pola finura erudita e polo interese das transcricións e recuperacións documentais; aportacións valiosas, anque insuficientes, por terse realizado desde un insuficiente coñecemento da historia da educación.

$\mathrm{Na}$ actual evolución da historia da educación sobresae a influencia formativa e o traballo realizado en particular desde a Sección de Pedagoxía da Universidade de Santiago, tanto a través da realización de teses de doutoramento como a través do traballo e iniciación na investigación histórico-educativa que se leva a cabo cos alumnos de Historia da Educación, autores xa hoxe dun notable volume de monografías, de traballos de campo, e de búsquedas documentais e bibliográficas. Complementariamente sinalamos unha presencia considerable da producción histórica en lingua galega que non sempre trascende os lindeiros xeográficos galegos, así como o protagonismo de profesoras universitarias neste proxecto e proceso de construcción da historia da educación en Galicia.

\section{BIBLIOGRAFÍA}

\section{Libros}

BARRERA PENA, M.L.; LOPEZ PEÑA, A.: Sociología de la mujer en la Universidad. Análisis histórico-comparativo Galicia-España 19001931. Publics. Universidade de Santiago, 1983.

BARREIRO FERNÁNDEZ: "La enseñanza en Galicia en la época contemporánea", Historia Contemporánea de Galicia III, Gamma, A Coruña, 1982, pp. 15-128.

CABEZA DE LEÓN, FERNÁNDEZ VILLAMIL (Con prólog de PEDRET CASADO), Historia de la Pontificia, Real e Insigne Universidad de Santiago, Bibliófilos Gallegos, Santiago, 1945-47, 3 vols.

CID FERNÁNDEZ, X.M.: Educación e Ideoloxía en Ourense na II ${ }^{a}$ República Universidade de Santiago, Santiago, 1989.

CID FERNÁNDEZ, X.M.: Apuntes da nosa historia escolar, Nova Escola Galega, Concello de Ourense, Ourense, 1989. 
COSTA RICO, A.: Escolas e Mestres. A educación en Galicia: da Restauración á II República, Xunta de Galicia, Santiago, 1989.

COUSELO BOUZAS: Fray Rafael de Velez y el Seminario de Santiago, Tip. del Seminario C. Central, Santiago, 1927.

DÍAZ DÍAZ, M. (Coord.): La Universidad de Santiago, Universidad de Santiago, Santiago, 1980.

FRAGA VÁZQUEZ, G.: El Seminario Diocesano de Lugo, Fundación Caixa Galicia, A Coruña, 1989.

GABRIEL FERNÁNDEZ, N.: Agricultura e Escola. Contra a rutina e o éxodo escolar, Universidade de Santiago, Santiago, 1989.

GABRIEL FERNÁNDEZ, N.: Leer, escribir y contar. Escolarización popular y Sociedad en Galicia (1875-1990), Do Castro, Sada, 1990.

GALINO, Ma A.: Tres hombres $y$ un problema: Feijoo, Sarmiento y Jovellanos ante la educación moderna, CSIC, Madrid, 1953.

LEIRÓS FERNÁNDEZ: El Padre Feijoo. Su Magisterio. Antología de sus obras, La Voz de la Verdad, Lugo, 1967.

MAYOBRE, P.: Debates ideolóxicos na Compostela do XIX, Do Castro, Sada, 1985.

MEIJIDE PARDO, A.: Origen y progresos de la Escuela de Náutica de La Coruña (1790-1825), Publics. de la Real Academia Gallega, A Coruña, 1963.

MEIJIDE PARDO, A.: La Academia y Escuela de Bellas Artes de La Coruña, Diputación de La Coruña, A Coruña, 1989.

OTERO URTAZA: Las Misiones Pedagógicas en Galicia, Do Castro, Sada.

OVILO y OTERO, M.: Hijos Ilustres de la Universidad de Santiago, Imp. de La Gaceta de Galicia, Santiago, 1880.

"CUADERNOS DE ESTUDIOS GALLEGOS", Tomo XLI, Fascículo 106, Santiago 1993-94. 
PEÑA SAAVEDRA: Exodo, organización comunitaria e intervención escolar. La impronta educativa de la emigración transoceánica en Galicia, Xunta de Galicia, A Coruña, 1991, 2 vols.

PEREIRA DOMÍNGUEZ, M.C.: La labor educativa iberoamericana y la creación de las escuelas Pro Valle Miñor, Universidad Complutense, Madrid, 1988.

PEREIRA DOMÍNGUEZ, M.C.: La obra socio-educativa realizada por la Caja de Ahorros Municipal de Vigo a través de las Colonias Escolares (1927-1983), La Voz de Galicia, A Coruña, 1991.

PÉREZ BUSTAMANTE, C.; GONZÁLEZ GARCÍA-PAZ: La Universidad de Santiago (El pasado y el presente), Santiago, 1934.

PORTO UCHA, A.S.: La Institución Libre de Enseñanza en Galicia, Do Castro, Sada, 1986.

POUSA ANTELO, A.:

PRADO GÓMEZ, A.: La Diputación Provincial de Lugo y los inicios de la institución pública en Lugo, Diputación Provincial de Lugo, Lugo, 1990.

RIVERA VÁZQUEZ, E.: Galicia y los Jesuitas. Sus colegios y enseñanza en los siglos XVI al XVIII, Fundación Barrié, A Coruña, 1989.

ROMÁN PORTAS, L.: La asistencia social en Galicia: el hospicio de pobres de Santiago de Compostela (1860-1900), Diputación Provincial, A Coruña, 1989.

SAÍNZ AMOR, C.: Ideas pedagógicas del P. Feijoo, CSIC, Madrid, 1946.

SÁNCHEZ CANTÓN, F.J.: Ideas de los P.P. Feijoo y Sarmiento sobre la organización de los estudios, Universidad de Oviedo, Oviedo, 1961.

SOUSA, J.; PEREIRA, F.: Historia de la Escuela de Artes y Oficios de Santiago de Compostela, Diputación de La Coruña, A Coruña, 1988. 
TORRES REGUEIRO, X.:Xoan Vicente Viqueira e o nacionalismo galego, Do Castro, Sada, 1987.

VARELA GONZÁLEZ, I.: La Universidad de Santiago, 1900-1936. Reforma Universitaria y conflicto estudiantil, Do Castro, Sada, 1990.

VIDAL ABASCAL, E.: Influencia de algunos matemáticos y universitarios en el Renacimiento Cultural de Galicia, Santiago, 1973.

\section{Outros Traballos}

ARES FARALDO: "La Cátedra de Latinidad de Betanzos", Anuario Brigantino, 13 (1990) 55-58.

BARREIRO FERNÁNDEZ, RODRÍGUEZ DÍAZ, RUIBAL SOBRAL: "El Evolucionismo en Galicia en el siglo XIX. Hipótesis interpretativa del atraso de la ciencia en España durante la segunda mitad del siglo XIX", Compostellanum, (1971) 539-574.

- "Los Comienzos de la reforma del Colegio de Fonseca en 1748-51 y su incidencia en la primera reforma universitaria española" Liceo Franciscano, 82-84 (1975) 215-233.

BARREIRO RODRÍGUEZ, H.: "Hacia una nueva historia de la educación en Galicia. Algunas cuestiones de método", Bordón, 253 (1984) 399-403.

BENSO CALVO, C.: "Escuela y Sociedad en Ourense (1940-1970), Actas II ${ }^{\circ}$ Coloquio Español de Historia de la Educación. Escolarización y Sociedad en la España Contemporánea, Universidad de Valencia, Valencia, 1983, pp. 565-579.

- "Escolarización e Sociedade en Ourense. Modalidades, niveis e funcións da escolarización na sociedad ourensana franquista" VVAA, Educación e Sociedade en Ourense, Do Castro, A Coruña, 1989.

- "Mujer y prensa agraria en Galicia. Análisis de La Zarpa (1921-23)", Actas VI Coloquio Español de Historia de la Educación. Muller e Educación en España (1868-1975), Universidade de Santiago, Santiago, 1990 (en colaboración con I. Nogueira Blanco).

- "La Mujer en el discurso del Catolicismo. Análisis de La Región (1921-23)", Ibid.

"CUADERNOS DE ESTUDIOS GALLEGOS", Tomo XLI, Fascículo 106, Santiago 1993-94. 
- "Educación y Sociedad en Orense a mediados del siglo XIX. La puesta en marcha del nuevo Instituto Provincial", Historia de la Educación, 9 (1990) 197-218.

BREY GERARD: "L'enseignement populaire non oficiel en Galice urbaine jusqu'en 1911" C.I.R.E.M.I.A., L'enseignement primaire en Espagne et en Amerique Latine du XVIII siècle a nos jours, Université de Tours, 1987, pp. 195-210.

CARIDE GÓMEZ, J.A.: "Política educativa, escolarización rural y práctica social en Galicia (1939-1970)", Actas III Coloquio Español de Historia de la Educación Escolarización y Sociedad en la España Contemporánea. Universidad de Valencia, Valencia, 1983, pp. 599616.

CID FERNÁNDEZ, X.M.: "Postura controvertida de A. Couceiro Freijomil ante o rexurdimento e extensión da conciencia nacionalista (19161936)", Boletín Auriense, XII (1982) 275-297.

- "Aportaciones del Ayuntamiento y la Diputación de Ourense a la democratización de la enseñanza (1931-36)", Actas del III Coloquio E. de $H^{a}$ de la Educación. Escolarización y Sociedad en la España Contemporánea, Valencia, 1983, pp. 617-630.

- "Tres alternativas educativas para a crase obreira e artesán de Ourense; Materiais Pedagóxicos, Universidade de Santiago, 1 (1985) 23-30.

- "El crecimiento urbano y la transformación de la escuela pública en Galicia (1916-36)", Actas de IX Jornadas d'Historia de l'Educació als Paisos Cataláns, Barcelona, 1987.

- "La Escuela Laica Neutral de Ourense en el marco de las realizaciones educativas de los emigrantes gallegos; Historia de las relaciones educativas entre España y América. Actas del $V^{o}$ Coloquio E. de $H^{a}$ de la Educación, Universidad de Sevilla, Sevilla, 1988.

- "Nova educación e galeguización do ensino na II República", Agalia, 15 (1988).

- "Na percura da escola pública. A loita do Maxisterio ourensán nos anos trinta", Revista Galega de Educación, 6 (1988).

COSTA RICO, A.: "O laicismo escolar en Galicia", Man Común, 3 (1980) 26-31.

- "El laicismo escolar en Galicia", Cuadernos de Pedagogía, 73 (1981) 69-72. 
- "Instituciones para la formación de los maestros gallegos en los finales del siglo XIX", Historia de la Educación, 2 (1983) 189-198.

- "Rol, situación y comportamiento de los maestros rurales gallegos en los finales del siglo XIX" Actas del III Coloquio E. de Ha de la Educación, op. cit., Valencia, 1983, pp. 631-644.

- "Magisterio (El Magisterio Gallego en el primer tercio del siglo XX)", Gran Enciclopedia Gallega, 307-8 (1983) 42-50.

- "Propuestas educativas en el medio rural gallego en el primer tercio del siglo XX", Sisenes jornadas d'Historia de l'Educació als Paisos Cataláns. Actas, Lleida, 1984, pp. 334-346.

- "Publicaciones pedagógicas y escolares en la historia contemporánea de Galicia", Bordón, 253 (1984) 421-435.

- La emigración gallega y su acción cultural-educativa en sus lugares de origen", Cuadernos del Norte (Oviedo), 1984, pp. 35-44.

- O galeguismo e o debate escolar (coa colaboración de Narciso DE GABRIEL), Dirección X. de Política Lingüística / Consellería de Educación, Actas das II Xornadas de Lingua Galega, Santiago, 1985.

- "Sociedades de Instrucción (coa colaboración de Vicente PEÑA SAAVEDRA), Gran Enciclopedia Gallega, 1985.

- "O desenvolvemento pedagóxico europeo e o seu coñecemento na Galicia do primeiro tercio", Materiais Pedagóxicos, Universidade de Santiago, 2 (1986) 15-19.

- "Socialismo e educación na Galicia do primeiro tercio do século XX", JUANA J., CASTRO, X. (Coords.), Actas II Xornadas de Historia de Galicia, Deputación de Ourense, Ourense, 1986, pp. 135-164.

- "Da escola da palabra e da cidadanía á escola do silencio", A NOSA TERRA, A nosa historia / 2. Os anos despois (1936-1953), 1987.

- "A longa historia do sindicalismo no ensino en Galicia", Revista Galega de Educación, 5 (1987) 57-59.

- "A Institución libre de Enseñanza en Betanzos", Anuario Brigantino, 11 (1988).

CUESTA GUTIÉRREZ, L.: "La Universidad gallega: Su pasado, su presente y su porvenir", Boletín de la Universidad de Santiago, 8 (192930) 3-19.

- "Los orígenes de la Biblioteca Universitaria de Santiago", Boletín de la Universidad de Santiago, 11 (1930-31) 3-28. 
DASAIRAS, X.: "García Barbón e o ensino no seu tempo", Revista Galega de Educación, 4 (1987), 67-71.

DÍAZ-FIERROS VIQUEIRA: "Comenzos da Ciencia Moderna na Universidade Compostelana", Compostellanum, XVI (1971) 387-423. - "La Cultura Científica", VVAA, Los Gallegos, Istmo, Madrid, 1976, 423-460.

ERIAS MARTÍNEZ, A.: Vales Villamarín. Lembranza no Centenario do seu nacemento, Concello de Betanzos, Betanzos, 1991, 52 pp.

FARIÑA CASALDARNOS, $M^{\text {a }}$ C.: "El profesorado y su situación profesional. Un estudio realizado a través del Archivo del Instituto Gelmírez de Santiago", Materiais Pedagóxicos, 2 (1986) 29-34.

- "La cátedra de latinidad a través de los planes de estudios", Historia de la Educación, 6 (1987) 183-191.

- "Informe del Rectorado de Santiago de Compostela sobre la fundación de un Instituto de Segunda Enseñanza en la ciudad de La Coruña (1959-1862)" Concepción Arenal. Ciencias y Humanidades (Ferrol), 17 (1987) 27-40.

FERNÁNDEZ CASANOVA: "La Sociedad Económica de Santiago y la Enseñanza", La Sociedad Económica de Amigos del País de Santiago en el siglo XIX, Do Castro, A Coruña, 1981, pp. 83-100.

FERNÁNDEZ VILLAMIL: La Ilustración y la enseñanza en Galicia. Relaciones con el Reino", Juntas del Reino de Galicia, Instituto de Estudios Políticos, Madrid, 1962, T. III, pp. 445-463.

FIGUEROA/PANISSE, X.L. FONTENLA: "Un precursor da inovaçóm pedagogica galega do século XVIII: o Padre Sarmiento", O Ensino, 710 (1985) 81-92.

FILGUEIRA IGLESIAS, A.: "Lengua materna y educación en Fray Martín Sarmiento", Cuadernos de Estudios Gallegos, 81-83 (1972) 191272.

FRAGA VÁZQUEZ, X.A.: "Aportación ao estudio da polémica administa na Galicia do século XIX", Actas II Congreso de la Sociedad Españo-

"CUADERNOS DE ESTUDIOS GALLEGOS", Tomo XLI, Fascículo 106, Santiago 1993-94. 
la de Historia de las Ciencias, Jaca, 1984, T. I., pp. 371-387.

- "A propagación e institucionalización das Ciencias Naturais na Galicia no período 1868-1904: Villa Nadal", Actas III Congreso de la Sociedad Española de $H^{a}$ de las Ciencias, S. Sebastián, 1984.

- "Antonio Vila Nadal e as Ciencias Naturais", Ciencias. Revista de Enseñanza, 9 e 10 (1990) 5-17.

GELABERT, J.E.: "Niveaux d'alphabetisation en Galice (1635-1900), VVAA, De l'alphabetisation aux circuits du livre en Espagne: $X V^{e_{-}}$ XIXe siècles, Université de Toulousse, 1987.

GABRIEL FERNÁNDEZ, N.: "La Agricultura y la Escuela en España (1948-1901), Historia de la Educación, 2 (1983) 131-141.

- "El acceso de la mujer gallega a la cultura escrita en el siglo XIX", Bordón, 253 (1984) 437-448.

- "As Escolas de Ferrado na Galicia de século XIX", CASTRO, X., JUANA, J., (Coords.), Actas das III Xornadas de Historia de Galicia, Deputación de Ourense, Ourense, 1986, pp. 130-160.

- "Escolarización y sistemas de enseñanza", Historia de la Educación, 6 (1987) 209-227.

- "Financiación de la escuela pública en la España del siglo XIX. El Caso gallego", Historia de la Educación, 7 (1988) 163-178.

- "Maestras, escuelas mixtas y moralidad en la Galicia del siglo XIX", Revista de Educación, 285 (1988) 217-229.

- "Escolarización e práctica lingüística na Galiza rural do século XIX", Agalia, 13 (1988) 35-55.

- "O Congreso Pedagóxico de Barcelona (1888) e a reivindicaçon didáctica da lingua galega", Agalia, 17 (1989) 16-31.

- "Los resultados de la enseñanza en la escuela pública gallega durante el último cuarto del siglo XIX", Revista de Educación, 288 (1989) 237-254.

- "La mujer como maestra", Actas del VI Coloquio Esp. de $H^{a}$ de la Educación, op. cit., Universidade de Santiago, 1990.

GARCÍA CORTÉS, C.: "El Seminario Conciliar de Santiago. Nuevos datos para la historia", Compostellanum, XXVI, 1981.

- "El profesorado del Seminario Conciliar de Santiago y su labor científico-docente en la etapa universitaria (1876-1932)", Compostellanum, 3-4 (1982) 217-284.

"CUADERNOS DE ESTUDIOS GALLEGOS", Tomo XLI, Fascículo 106, Santiago 1993-94. 
LAGE CASAL: Castelao e a cuestión do ensino, Xunta de Galicia, 1990.

LANZA ÁLVAREZ, F.: "O ensino en Ribadeo dende o século XVI ó XIX", Falan os de Ribadeo, Do Castro, 1974, pp. 87-108.

LIÑARES GIRAUT, A.: "Ensino, emigración e Cultura", O Val de Barcala (1900-1936). Agrarismo, vida política, emigración e Cultura, Feiraco, Negreira, 1986, pp. 219-270.

MARTÍNEZ RODRÍGUEZ, E.: "La etapa reformista (1748-1845). Ciencia moderna y centralización", DÍAZ DIAZ (Coord.), La Universidad de Santiago, 1980, op. cit., pp. 37-48.

- "Pedro Bedoya y la Facultad de Medicina de Santiago", Compostellanum, 1-2 (1982) 93-111.

MEIJIDE PARDO, A.: "Apuntes sobre la tentativa de crear en Pontevedra una Escuela de Náutica (1769-1772)" El Museo de Pontevedra, XXXVII (1983) 135-156.

- "Apontamentos sobor dunha escola de debuxo e pintura establecida en Ourense a meados do s. XIX", Boletín Auriense, XVII-XIX (198889), 231-240.

- "La enseñanza secundaria en Betanzos en el siglo XIX: el Instituto Libre y los colegios privados" Anuario Brigantino, 13 (1900) 117-136.

MORANDEIRA ROEL, P.: "Mapa Escolar de la Antigua Provincia de Betanzos na segunda década do século XIX", Anuario Brigantino, 12 (1990) 99-114.

NOVOA GIL, ANA Ma: "As ideas pedagóxicas de J.V. Viqueira", $O$ Ensino, 7-10 (1985) 67-80.

OTERO PEDRAYO, R.: "Sobre algunos establecimientos de enseñanza en la Galicia del siglo XIX", Boletín de la Real Academia Gallega, 3334 (1961) 234-240.

OTERO TUÑEZ: "Los últimos vítores de la Universidad Compostelana" Cuadernos de Estudios Gallegos XXV (1970) 290-298.

PENSADO, J.L.: "Los estudios gallegos de Sarmiento. Su estructura", Cuadernos de Estudios Gallegos, 81-83 (1972).

"CUADERNOS DE ESTUDIOS GALLEGOS", Tomo XLI, Fascículo 106, Santiago 1993-94. 
PEÑA SAAVEDRA, V.: "Tres aspectos del proyecto escolar de los emigrantes gallegos: instalaciones, equipamiento y personal docente", Bordón, 253 (1984) 405-420.

- "Presupuestos socio-educativos para la implantación de Sociedades de Americanos y Sociedades de Instrucción", Historia de la Educación, 2 (1984) 359-369.

- "A obra socio-educativa dos emigrantes orteganos" Encrucillada, 36 (1984) 28-36.

- Apuntes autobiográficos de Ramón Armada Teixeiro, Imp. Fojo, Ortigueira, 1984, $11 \mathrm{pp}$.

- "Difusión y enseñanza de la Constitución durante el Trienio Liberal (1820-23), Las obligaciones de los profesores y los curas párrocos", Materiais Pedagóxicos, Universidade de Santiago, 1 (1985) 15-24.

- "A primeria prensa escolar ortegana: xénese e desenvolvemento dunha experiencia precursora", VVAA, Miscelánea de estudios históricos das Terras de Ortegal. Ponencias, Imp. Fojo. Ortigueira, 1989, pp. 75-91.

- "La Voz de Ortigueira e a temática educativa", CELEIRO ÁLVAREZ, El Escolar. El Faro de Veiga. La Voz de Ortigueira, Xunta de Galicia, 1989, pp. 123-131.

- "Un proceso sostido de renovación educativa: Ortigueira, 1900-1936", VVAA, Miscelánea..., op. cit., Ortigueira, 1989, pp. 45-62.

- "Cultura e educación na prensa ortegana durante o primeiro tercio do Século XX", in Cen anos de xornalismo ortegano 1889-1989, Ortigueira, Imp. Fojo, 1989, pp. 43-48.

PEREIRA DOMÍNGUEZ, M.C.: "La primera Colonia Escolar de Galicia (Santiago, 1893), Historia de la Educación, 2 (1983) 199-208.

- "La búsqueda de docentes cualificados, cuestión vital en el proyecto educativo promovido por los emigrantes gallegos en América a principios del siglo XIX", Actas del V Coloquio Esp. de $H^{a}$ de la Educación, op. cit., Universidad de Sevilla, Sevilla, 1988, pp. 426-431.

PEREIRA, F.; SOUSA, J.: "El origen de las Escuelas de Artes y Oficios de Galicia. El Caso Compostelano", Historia de la Educación, 9 (1990) 219-232.

PÉREZ PAIS, $\mathrm{M}^{\mathrm{a}} \mathrm{L}^{\mathrm{a}}$ : (coa colaboración de COSTA RICO), "Prensa escolar (1842-1936)", Gran Enciclopedia Gallega, 399 (1985) 231-2.

PORTO UCHA, A.: "Contribución de la Escuela de Artes y Oficios de 
Vigo a la formación de la clase obrera a fines del siglo XIX", Actas del III Coloquio Español de Historia de la Educación, op. cit., Valencia, 1983, pp. 493-505.

- "El Plan y Método de Educación de D. Manuel Lameyro y García en la Galicia de la Ilustración", Actas del III Coloquio Español de Historia de la Educación, Universitat de Barcelona, 1984, pp. 164-172.

- "Las Misiones Pedagógicas en Galicia: un modelo de educación popular durante la II República", Actas de las VIII Jornadas d'Historia de l'Educació als Paísos Cataláns, Menorca, 1986, pp. 135-143.

- "La postura de la Iglesia Gallega ante el tema de la enseñanza a través de los Boletines Eclesiásticos durante la Restauración", Actas del IV Coloquio Español de Historia de la Educación, Iglesia y Educación en España. Perspectivas históricas, ICE, Palma, 1986, pp. 253-263.

- "Institucionismo e galeguismo en X.V. Viqueira", Grial, 98 (1987) 499-503.

- "La Escuelas de Artes y oficios en Galicia y su contribución al desarrollo del mundo urbnao (1886-1902)", Actas de las IX Jornadas d'Historia de l'Educació als Paísos Cataláns, Barcelona, 1987, pp. 345-355.

- "El institucionismo en Galicia. Aproximación al esquema organizativo de la Misión Biológica de Galicia en su primera época (1921-1936)", Boletín de la Institución Libre de Enseñanza, 5 (1988) 89-98.

- "A política educativa na Restauración: o estancamento do ensino primario na Galiza", O Ensino, 23-28 (1988), 163-172.

- "Contribución de las Sociedades Gallegas de Instrucción en América a la creación de la Residencia de Estudiantes de la Universidad de Santiago (1926-1936)", Actas del V Coloquio Español de Historia de la Educación, op. cit., Sevilla, 1988, pp. 432-440.

- "O maxisterio pontevedrés no período republicano", Revista Galega de Educación, 8 (1989) 58-61.

- "El acceso de la mujer gallega al magisterio primario: la Escuela Normal de Maestras de Pontevedra en el siglo XIX (1860-1901)", Actas del VI Coloquio Español de Historia de la Educación, op. cit., Santiago, 1990.

- "Repercusiones de la Revolución Francesa en Galicia: la lectura de libros prohibidos", G. OSSENBACH SAUTER, PUELLES BENITES (Coords.), La Revolución Francesa y su influencia en la educación en España, UNED, Madrid, 1990, pp. 355-370.

- "A formación do profesorado galego: A Xunta para Ampliación de estudios e as viaxes a Europa (1907-1936), Adaxe 5 (1989) 81-90. 
- Institucións complementarias no contexto da Escola primaria: As Colonias Escolares da Universidade de Santiago de Compostela (192325) Adaxe, 1991, nº 6, pp. 83-96.

REY, E.; CASTRO, A.: "Historia de a Fundación Fernando Blanco, de Cee", Compostellanum, 1-4 (1974) 239-300.

REY CASTELAO, O.: "La Universidad en las épocas clásica y barroca", DÍAZ DÍAZ (Coord.), La Universidad de Santiago, op. cit., 1980, 2336.

SÁNCHEZ CANTOS, F.J.: "Anticipaciones del P. Sarmiento en materia de enseñanza", Cuadernos de Estudios Gallegos, 81-83 (1972).

SÁNCHEZ RODRÍGUEZ DE CASTRO, M.C.: "Las enseñanzas técnicas en La Coruña a finales del siglo XVIII", Materiais Pedagóxicos, 2 (1986) 35-43.

SUÁREZ PAZOS, M.: "Actividades das Xuntas Revolucionarias Galegas na educación, 1868", Boletín Auriense, X (1980) 119-129.

- "El campesinado gallego y su rechazo a la escuela primaria (18681874)", Historia de la Educación, (1984) 317-324.

- "A educación primaria da muller galega (1868-1874), Revista Galega de Educación, 1 (1986) 63-66.

- "Imagen socio-educativa de la mujer gallega en el Sexenio Revolucionario (1868-1874)", Actas del VI Coloquio Español de Historia de la Educación, op. cit. Universidade de Santiago, 1990.

VALÍN FERNÁNDEZ, A.: "El laicismo, la enseñanza y la mujer en la historia de Galicia. Apuntes varios para un estudio", Actas del VI Coloquio Español de Historia de la Educación, op. cit., Universidade de Santiago, 1990.

VARELA GONZÁLEZ: "Aspectos de la Universidad en el período Isabelino (1833-1868)", DÍAZ DÍAZ (Coord.), La Universidad de Santiago, op. cit., 1980, pp. 67-76.

VIÑAS, J.J.: "Breve reseña de la Universidad de Santiago", Anales de Universidad de Santiago, (1856-57) 5-50. 